\title{
African indigenous care-giving practices: Stimulating early childhood development and education in Kenya
}

\begin{tabular}{|c|c|}
\hline \multicolumn{2}{|c|}{$\begin{array}{l}\text { Authors: } \\
\text { Pamela Wadende } \\
\text { Paul O. Oburu }^{1} \\
\text { Abel Morara }^{3}\end{array}$} \\
\hline \multicolumn{2}{|c|}{$\begin{array}{l}\text { Affiliations: } \\
{ }^{1} \text { Department of Education, } \\
\text { School of Education and } \\
\text { Human Resource } \\
\text { Development, Kisii University, } \\
\text { Kenya }\end{array}$} \\
\hline \multicolumn{2}{|c|}{$\begin{array}{l}{ }^{2} \text { Department of Educational } \\
\text { Psychology, Maseno } \\
\text { University, Kenya }\end{array}$} \\
\hline \multicolumn{2}{|c|}{$\begin{array}{l}{ }^{3} \text { Pamela Scott Leldet } \\
\text { Secondary School, Kenya }\end{array}$} \\
\hline \multicolumn{2}{|c|}{$\begin{array}{l}\text { Corresponding author: } \\
\text { Pamela Wadende, } \\
\text { pamela.wadende@gmail.com }\end{array}$} \\
\hline \multicolumn{2}{|c|}{$\begin{array}{l}\text { Dates: } \\
\text { Received: } 13 \text { May } 2016 \\
\text { Accepted: } 20 \text { Oct. } 2016 \\
\text { Published: } 03 \text { Dec. } 2016\end{array}$} \\
\hline \multicolumn{2}{|c|}{$\begin{array}{l}\text { How to cite this article: } \\
\text { Wadende, P., Oburu, P.O. } \\
\text { \& Morara, A., 2016, 'African } \\
\text { indigenous care-giving } \\
\text { practices: Stimulating early } \\
\text { childhood development and } \\
\text { education in Kenya', } \\
\text { South African Journal of } \\
\text { Childhood Education 6(2), } \\
\text { a446. http://dx.doi. } \\
\text { org/10.4102/sajce.v6i2.446 }\end{array}$} \\
\hline \multicolumn{2}{|c|}{$\begin{array}{l}\text { Copyright: } \\
\text { (C) 2016. The Authors. } \\
\text { Licensee: AOSIS. This } \\
\text { is licensed under the } \\
\text { Creative Commons } \\
\text { Attribution License. }\end{array}$} \\
\hline \multicolumn{2}{|l|}{ Read online: } \\
\hline 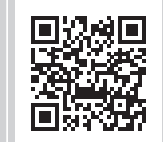 & $\begin{array}{l}\text { Scan this QR } \\
\text { code with your } \\
\text { smart phone or } \\
\text { mobile device } \\
\text { to read online. }\end{array}$ \\
\hline
\end{tabular}

The indigenous communities in Africa, specifically Kenya, which is the focus of this article, had their own well-developed motivational systems that positively enhanced teaching and learning programmes in the community. These motivational systems were manifested in behaviours that were presented as sequential cultural tasks that demanded active engagement from children at every stage of development. The philosophical tenets of African indigenous education underscored education as preparation for life. This was a culturally based education that addressed the physical, emotional, mental and social aspects of a child's successful development. It offered the child an opportunity to participate in practical, productive and responsible livelihood activities. This article suggests that a concert of research into these indigenous motivational care-giving practices and community participation in the activities of early childhood education may offer important insights into transitioning children from life in the home environment to that of the school and its accompanying academic tasks. When these motivational care-giving practices are incorporated in the process of transitioning children to formal schooling, then their chances of success in these new educational programmes could be enhanced.

\section{Introduction}

This article reviews sampled studies that have been conducted in Africa, whose focus has been surveying and collecting aspects of indigenous learning and motivational practices. No doubt, there exist a lot of studies that did not contribute to the conclusions made in this article. Additionally, there are findings in the reviewed studies that were not incorporated in the conclusions made in this article. Many studies have consistently indicated that African indigenous communities, specifically in Kenya - the focus of this article - had their own well-developed motivational systems that positively enhanced teaching and learning programmes in the community (Segall et al. 1999; Wadende 2011). Motivation involves giving guidance towards a desired goal acceptable as good behaviour in the community. These motivational systems were manifested in behaviours that were presented as sequential cultural tasks (tasks that spell prerequisite skills for acceptance into the training of successive skills) that a child was expected to accomplish at different stages of development and for which active or participatory engagement was a necessity (Nsamenang 1992, 2004, 2008; Rogof 2003). The successful accomplishment of such tasks, for example, cleaning themselves or baby-sitting their siblings, was of immediate efficacy to the child and his community and allowed them to be trained for new skills to build into what they already knew. African indigenous education utilised motivational practices to enhance the child's preparedness for engagement in goal-directed behaviours that were deeply rooted in tradition. These behaviours were practical and, in most cases, a preparation for acquisition of requisite lifelong skills. The behaviours covered all aspects of life (physical, emotional, mental and social) and focused on the development of their community of origin (Sifuna 1990). This, then, was a culturally based education that addressed the physical, emotional, mental and social aspects of a child's successful development. This education also offered the child an opportunity to participate in practical, productive and responsible livelihood activities (Nsamenang 2004).

It is the suggestion of this article that research and application of research findings on aspects of Indigenous Motivational Care-giving Practices (IMCP) and sustained community involvement in the Early Childhood Development (ECD) centres could be useful in transitioning children from life in the home environment to that of the school and its accompanying academic tasks. This transition process may be useful in many African communities, including the Kenyan communities in which children are exposed to the IMCP practices in their initial years of life. It is important to note that even such children as previously described may already be exposed to aspects of formal school tasks through interaction with siblings and other children already enrolled in formal schooling programmes in their community. Notwithstanding, both the institutionalised early childhood development and education (ECDE) centres and the academic tasks expected of the 
child in them may prove new to such a child even though their aim is to develop the child holistically (NACECE 2006) as is the aim of African indigenous education for the community (Sifuna 1990). Indeed, it is commonly the expectation the world over that children begin formal, institutionalised schooling as soon as they have attained a level of independence deemed appropriate for the initial levels of education and that these levels develop their whole personality which include their physical, intellectual, cultural, spiritual and mental faculties (KIE 2002). This article suggests that the inclusion of IMCP in the process of transitioning children to formal school and academic tasks may enhance their chances of success in these new programmes. Such a transitioning process would acknowledge the educational principle that acquisition of new knowledge is more successful when done from the known to the unknown.

\section{Early childhood development and education in Kenya: An overview}

The social constructivist theory as advanced by Lev Vygotsky foregrounds culture as a key source of knowledge in the community (Vygotsky 1968). According to this theory, the society behaves according to the way its members mould it. The theory states that social interaction plays a fundamental role in the process of cognitive development. Vygotsky focused on connections between people and the sociocultural context in which they act and interact in shared experiences. A major focus of social constructivism is to uncover the ways in which individuals and groups participate in the construction of their perceived social reality. It involves investigating the ways in which social phenomena are created, institutionalised, known and made into tradition by humans.

Accordingly, a child's intellectual development depends on early interaction and exposure in the home environment. Most children in the society are under care of parents and caregivers who still adhere to traditions and norms passed down from one generation to the next. Although culture is dynamic and society easily embraces new aspects of life as they emerge and discards practices that have proved obsolete, some child caregivers may still preserve views propagated by ways of life that may be no longer useful to the children. For example, commonly in African communities, the boy is socialised to do male chores and girls the stereotypically female chores. Social constructivists believe that one behaves in the way his or her society requires. The society moulds an individual in such a way that he or she abides by its rules which are already spelt out in an unwritten curriculum in many African communities (Segall et al. 1999; Wadende 2011).

The IMCP have always had an unwritten curriculum that emphasised the child's cultural knowledge. The curriculum also spelt adults' acknowledgement of these children's developmental stages especially in respect to capacities to carry out various tasks (Nsamenang 2008). This is a highly participation-based education that would almost always engage the learner's three domains of learning - the affective, cognitive and psychomotor - in accomplishing the set tasks. Thus, the importance of adapting relevant practices of this kind of participatory and holistic learning to the enhancement of ECDE programmes cannot be gainsaid in view of the numbers of children that enrol in this level of formal education in Kenya. For example, based on Kenya's Ministry of Education, Science and Technology (MOEST) and UNESCO 2005 estimates, over 1.5 million children (representing $35 \%$ of all the children in this age-group) were enrolled in preschools in Kenya. This enrolment is too low, given that the most efficient time for fostering human growth and development is the first 6 years of life (Githinji \& Kanga 2011). Although this enrolment is arguably low, it is still important that the children thus registered in ECDE programmes are afforded the best chances of academic and social development by programmes at this level of education. Such children, also, need to be offered a good educational foundation at this level so they can be poised to successfully engage educational tasks in succeeding stages of schooling.

In life, smooth transitions from one stage to another are often a predictor to success in the new tasks encountered. Consequently, a good educational foundation at the ECDE level by necessity requires that the child has a smooth transition from the motivational and educational practices in their familiar home environment to the comparable practices in the ECDE institution environment. The preceding discussion points to a need for relevant teaching and learning practices for the ECDE level of schooling that has some aspect of IMCP that a child may be already familiar with. According to the (UNESCO 2005) report on Kenya's ECDE programme, this educational level should ideally focus on the holistic development of the child to enhance their success as learners. This is especially so because a poor ECDE programme can leave a lasting mark of deficiencies and impairment whose cost is manifested in poor health, disability, educational wastage, incompetence and delinquency (Schweinhart, Barnes \& Weikart 1997). Such an incompetent ECDE programme would add to the number of learners wasted in the educational system. It is notable that the holistic development of the child is also the focus of the indigenous care-giving practices, so amalgamation practices in the two programmes can only enhance ECDE services offered to the child.

As a result of reports such as the ones about the number of children enrolled in preschool, and in order to develop a successful citizenry, the Government of Kenya has consistently demonstrated her firm support for any efforts that promote the well-being of children aged between 0 and 18 years. One consequence of this commitment is that Kenya is a signatory to various international conventions that include the United Nations Convention on the Rights of Children (UNCRC) and the African Charter on the Rights and Welfare of the Child (ACRWC). The Kenyan government has not only been a signatory to these conventions, but has also reinterpreted them through national laws and policy guidelines aimed at benefiting the child. The reinterpretation of these conventions is contained in such efforts as the development of the Children's Act of 2001, the National Early 
Childhood Development Policy framework of 2006, the National Early Childhood Development Service Standard Guidelines of 2006 and Orphans and Vulnerable Children's Policy of 2005 (Indakwa \& Miriti 2010). Despite all these efforts by the Kenyan government, ECDE service provision in Kenya is fraught with planning weaknesses, and most of the programmes seem weak and unsustainable. Research into IMCP and sustained community involvement in ECDE programmes affirm the social constructionist ideas of knowledge acquisition and may offer a novel way of transitioning children from any educational programme they had in their home environment to the formal school programmes.

In Kenya, as in most developing countries, the early childhood years are defined as those from birth to 5 years in official documents such as the Education Sector Strategic Plan and National Action Plan on Education for All (MOEST 2003). However, the government initiated a large 7-year ECD project with the World Bank in 1997 for children aged 0-8 years, which addressed issues such as enhancing transition from ECD to primary schools. Since then, it started referring to ECD as care and education programmes catering to children from birth to 8 years old. Experts are in consensus that these early years of life are the most critical for the child as this is when the child learns the abilities presented in their affective, cognitive and psychomotor domains. The environmental experiences provided during this period are extremely significant; they determine whether the child develops into a successful and healthy adult (Myers 1998). From the preceding discussion, it is, therefore, important that ECDE programmes be strengthened so they can be sustainable and be able to afford the child a foundation for a successful future adulthood. One way of enhancing the depth and breadth (so that the traces of indigenous methods are also adapted beyond the ECDE levels, even if in gradually diminishing levels) of these programmes is through the conscious and sustained incorporation of indigenous motivational and care-giving methods.

\section{Unwritten curriculum for the indigenous motivational care-giving practices in Kenya}

As noted earlier, African indigenous education addressed the physical, emotional and social aspects of a child's healthy development with the community as a backdrop for the educational content. Through learning by doing, for example, a child would learn to take responsibility for himself and others in his group and of virtues such as hard work, friendship and truthfulness through play, story-telling sessions and practical assignments. The practical assignments included the aspects of tasks in the family that the child could effectively accomplish such as brief sessions of caring for a sibling, helping an older sibling or parent clean up or even prepare a meal. The notable aspect of the indigenous motivational and care-giving curriculum is that the learning objectives were achieved through sequential cultural skills that a child was expected to acquire through active participation in goal-oriented activities. The educational tasks were set in a progressive manner from relatively simple to more challenging assignments. The child could only achieve the objectives of the tasks through active participatory engagements in them. Such a programme developed in the child a love of learning and thus positioned them to be lifelong learners able to learn and adapt to changing times in the world. The programme also developed the child holistically and resulted in well-rounded members of the community able to actively participate in community processes over the years (Nsamenang 2004; Sifuna 1990).

The child was both intrinsically and extrinsically motivated to successfully accomplish the tasks set out for them in the indigenous educational and care-giving setup. The intrinsic and extrinsic motivation emanated from activities the child was involved in. Nsamenang (2006) in discussing the often unavailability of commercial toys for play by non-western children noted that this reality motivated the children to develop their own toys from available materials they could use. The successful creation of such toys, among other things, increased the child's self-worth and sense of belonging among their age-mates and the community at large.

There are similarities between the curriculum in the indigenous and the ECDE settings. Similar to the indigenous focus and approach to early childhood care and education, the ECDE approach should also prioritise the child's holistic development (KIE 2002) in line with theoretical and research findings of best practices in ECD and education. The indigenous and ECDE approaches both focus on a participatory type of learning based on cultural precepts, fulfilment of programme relevance and lifelong skills acquisition.

However, because of a generalised lack of documentation of motivational practices and the unwritten curriculum by the traditional learning approaches, there is an urgent need to determine these IMCP and their implications on the development of early childhood education programmes and services. This is necessary given that early childhood care - as commonly provided by parents, especially mothers, or other designated caregivers, such as house helps, grandmothers and older siblings (Oburu 2004; Swadener 1996) - is grounded in these important indigenous motivational practices and processes across the lifespan that remain largely undocumented for posterity.

\section{Challenges facing the early childhood development and education programmes in Kenya}

The challenges facing the ECDE programmes in Kenya emanate from both the central government and the community stakeholders. The ECDE providers are always in the middle, trying to satisfy the demands of these two very important sides in the provision of ECDE services. Indeed, the UNESCO (2005) report noted that the Kenyan ECDE programme is 
limited by the control it experiences especially from the central government and the conflicting interests from stakeholders. The stakeholders, such as parents, put pressure on preschools to teach their children what they deem as relevant school readiness skills such as numeracy and literacy (UNESCO 2005) at the expense of motivational life skills which are very important for the lifelong development of these children. School readiness skills are the ones the stakeholders feel would better prepare their children for the next levels of academic progression at primary school in Kenya. They make this conclusion without assessing the bigger picture that ECDE programmes should develop the whole child as do the indigenous educational learning programmes that a child is exposed to in their community (Nsamenang 2004).

Additionally, when parents insist that such ECDE centres only teach skills that prepare the children for formal primary schooling without delving into relevant motivational aspects that were emphasised in the traditional modules, it is likely that such children may be disadvantaged developmentally because of the narrowing of the focus to academic orientation. In such cases, the IMCP would prove an invaluable foundation for ECDE and other formal schooling programmes. This is because in the indigenous system of education, learners and community members had access to both general knowledge and specialised skills' acquisition that allowed them to live successfully in their environment (Kenyatta 1965).

Ultimately, there are some points of deviation between the two curriculums that include the setting - school versus home; some tasks that lack clear practicality and relevance to the child; 'artificial' demarcation of time for the various tasks set for the children; and some expectations which, at times, are new to the child. These include the expectation of individual excellence as opposed to the more used to communal or group excellence as presented in the communalism aspect of African indigenous education philosophy (Sifuna 1990).

Studies have shown that it is possible to incorporate the wishes of stakeholders into the ECDE programmes in order to offer children a holistic education that meets their community's expectations which enhances their retention in formal school programmes. A case in point is that of twinning Madarasa and ECD programmes among the Islamic communities at the Kenyan coast (Indakwa \& Miriti 2010). Islamic communities tend to offer religious education to children at a young age before they start attending formal schools. This education offered in Islamic schools is referred to as Madarasa. Commonly, this practice occurs at the expense of formal ECDE programmes. When children spend a number of their formative years enrolled in Madarasa and end up joining ECDE programmes late, they are more likely to be school drop outs. In order to retain such children in school while allowing them to also attend Madarasa programmes, the Kenya Community Development Foundation (KCDF) waged a sensitisation campaign in which they sought to integrate ECDE programmes with the Madarasa ones. This initiative received a lot of resistance from community members who perceived it as a ploy to diminish the importance of religious education for children. However, with intense lobbying and education programmes in which Islamic religious teachers were trained in formal education systems, the communities at last started accepting the integration idea of the two education and development programmes. This case may suggest the possibility of integrating more indigenous motivation and care-giving practices into the ECDE programmes to enhance the success of the children enrolled.

Enhancing local community involvement in the development of teaching resources not only acknowledges, as proposed by social constructivism theory, that social interaction plays a fundamental role in the process of cognitive development but also promotes the goodwill of the community to the centre and its programmes. In a related study, KCDF found that they could enhance community involvement in early childhood education and development through various activities that include building the ECD centres. At the coastal region of Kenya, parents and teachers pooled their effort to develop learning aids for their children. Teachers who had already been trained in the skill of developing these materials, in turn, trained the parents and community members on how to source suitable raw materials available in the community and how to create learning aids from the materials. These were active community participatory sessions that not only equipped the learning centres with suitable and exciting learning aids, but no doubt improved the community patronage of the learning centres. Community participation in the ECD centres in turn brought in aspects of the community's culture into the centre activities. These are the ways of life that the child is familiar and comfortable with. Such collaborative practices between the ECD centres and the local community acknowledge Vygotsky's (1968) social constructivism theory in its suggestion that a child's intellectual development depends on early interaction and exposure in the home environment. This exposure forms a good basis for formal school tasks as the child moves on to the school environment.

\section{Indigenous women child caregivers}

As revealed in the preceding discussion, women are commonly the caregivers for children in Kenyan families. They rely on indigenous practices that they learn and utilise from other learning ventures to accomplish this task. This reliance on indigenous practices learnt and utilised in other learning ventures was revealed in one study among Luo women collective in western Kenya (Wadende 2011). This study aimed at identifying the teaching and learning processes that women artists utilise in inducting their apprentices to the art forms of pottery, basketry and indigenous architecture. The study reported that learning these skills was done in a deliberately set up motivational system that also aimed at inculcating relevant life skills among members of the Luo community. The teaching, learning and production processes constituted an aspect of the adult learning agenda that the Luo women practise. Such community collectives of women have functioned to keep alive modified forms of these learning processes transferred from generation to generation along strictly maintained gender lines among the Luo since 
pre-colonial times. These activities and sites still enrich the creative opportunities of indigenous Luo women without extensive access to Western education, especially those living on rural traditional Luo lands.

More important and of relevance to this article is that this kind of education allowed these women a forum to learn child-rearing practices endorsed by their community. The women exchanged information about best practices in child rearing among other important knowledge. The indigenous creative processes provide adult learning, while enabling the women to generate some income, in the context of community development. It is also an opportunity for the women to bond and discuss important topical issues, while exchanging a wide range of skills and ideas ranging from domestic efficiency and economic exigencies to medical solutions. The creative teaching and learning processes pertinent to this study transpired in environments that were comfortable, welcoming and accepting. Participants in the study remarked that no one was excluded from these training sessions for lack of tuition fees. Such participants could pay for the training with their labour or other commodities they could produce.

The study further reported that some of the actively utilised aspects of motivation that eased the teaching and learning processes included singing, story-telling, imitation and use of proverbs and wise sayings. It also found that in addition to, and in the process of, learning these artistic skills, the artists shared other educational information quite unrelated to what they were learning, for example, they taught each other money management, cookery and child-raising skills.

The nature of the indigenous educational environment easily allowed the participants to learn the mentioned skills from each other. Participants in the study acknowledged that involving themselves in the indigenous teaching and learning processes made them deeply reflective members of the community. It allowed them the ability to seek a wide range of alternatives when facing life's various issues. Such an educational environment would have the same benefit for the developing child, who would be prepared to engage the various challenges and opportunities they would encounter in life's journey. Indeed, children do learn from their peers and teachers in the school environment. They learn from structured instruction in academic programmes and infer meanings from behaviours they observe in the school environment. The preceding argument suggests that even the development of contemporary ECDE programmes could be enhanced by the addition of motivational aspects of indigenous care-giving behaviours of Kenyan women, including but not limited to, house-help, grandmothers and older siblings (Oburu 2004; Swadener 1996). Information obtained from such an endeavour could thus form a rich data bank for the development of sound, context-relevant Early Childhood Education practices for posterity. This is so because educating the child forms a sizeable part of the caring process. Children at this stage learn from their environment, each other, and also depend on instruction and support from the caregivers to acquire relevant lifelong skills.

\section{Link between traditional motivational practices and early childhood development and education}

It would be useful to investigate and establish any links between traditional motivational learning practices and contemporary ECDE programmes. If such links could be established, they would have the potential to enrich scholarship in ECDE. In 2008, the United Nations International Child Emergency Fund (UNICEF) noted that although the majority (or 90\%) of children under 18 years in the world lived in developing countries, most of the research on ECDE was based on a unrepresentative number of children selected from the minority world. This is a point that has been echoed by other scholars conducting studies in the same field including Arnett (2008) and Marfo et al. (2011). According to the UNICEF and World Bank reports of 2010 and 2009, respectively, the participation of school-age children in Kenya's primary school education processes is estimated to be between $82 \%$ and $84 \%$ suggesting that even at this level there is a percentage of children that does not benefit from the advantages presented by participation in primary school education. These statistics point to a need for relevant research that aims to offer solutions to this problem of nonparticipation in primary school education. Additionally, although the management of ECDE is largely a communal affair rather than a government supported and sponsored endeavour (Swadener 1996), there is limited infusion of traditional knowledge from the local community into contemporary learning systems. The community's involvement is commonly peripheral and limited to providing financial and human resource for the running of such centres.

Consequently, current research may focus on the place of indigenous motivational learning systems in preparing children for formal schooling. Scholarship in the aforementioned area may be enhanced by the fact that some of the extant literature (e.g. Myers 1998; Schweinhart, Barnes \& Weikart 1993; Van der Gaag \& Tan 1998) has consistently indicated that a child's success in life depends on the balance struck between the inculcation of holistic knowledge and life skills in an environment that is conducive for the child's healthy development (Jaramillo \& Mingat 2008). In addition, five of the Millennium Development Goals (MDGs) as stated in the United Nations 2007 declaration also address the health, nutrition and education of young children as required human rights. Children represent the future. Any community improvement plans that fail to address the development and welfare of children may not be insightful as it does not fully address future success of the community. All these well-intentioned Millennium Goals, which address the well-being of children, also take cognisance of the fact that future preparedness also needs to take into account the children's traditional learning contexts during their formative years between birth and 6 years (Swadener 1996). 
In Kenya, preschool children are faced with numerous adjustment challenges during their first time in school. Such a child is, often, coming from a home environment where they engage in primed learning activities based on the African indigenous education principles and practices. Such traditional learning modules are in most cases practical, responsible and productive in addition to being a preparation for acquisition of necessary lifelong skills. The learning activities occur in the home setting, which for a child is often reassuring and motivating for the learning assignments set. The child is encouraged by all in the community as they attempt assignments. The assignments also have familiarity and practical relevance to the child as an active member of the community. Consequently, such a child may require that teachers, other children and adults who may be working in the same school environment be wholesomely engaged in his or her instruction or else they may become overwhelmed. It is also worth noting that the child at this time is also expected to make an about turn and start learning what is unfamiliar (such as the alphabet) which may not seem as 'productive and responsible livelihood activities' as is commonly practised in their home environments (Nsamenang 2004).

At preschool, these children are expected to successfully and instantly negotiate their way into new environments, often occupied and controlled by the other children, teachers and preschool staff. Additionally, these children are expected to succeed in their academic assignments in this new environment. All this is expected of children without any attempts made to offer them a transitional programme that would improve their chances of success when faced with all these changes. To ensure successful transition from the home into the preschool environment, there is a need to ensure a gradual shift from what children are familiar with to the new activities, methods, content and expectations in the preschool environment. Such a successful transition can be achieved when ECD and education providers identify the traditional motivational systems of learning and determine their links to current ECDE programmes. This process would then be followed by appropriately adapting the indigenous aspects into the current programmes.

\section{The case of global educational systems}

After all is said about the importance of incorporating indigenous teaching, learning and motivational practices into the formal education system, it is prudent to acknowledge the challenges that global education systems often face. Many times, it is the case that the children in any formal school classroom are drawn from diverse backgrounds. The pressure to offer a 'one-size-fits-all' educational experience is often great. To compound this pressure further is the dearth of research studies on practical ways of incorporating indigenous teaching and motivational practices into the formal educational system in a way that all children will benefit from the intervention. Education researchers may need to conduct studies whose finding may offer insight into how to incorporate aspects of African indigenous teaching and motivational practices in a way that supports the practices of formal school education but does not unduly advantage or disadvantage particular learners in school cohorts.

\section{Conclusion}

This article explored the possibility of the ECDE programmes borrowing from relevant indigenous motivational practices. These motivational practices have been successfully utilised, over time, to train children in the traditional settings. Before the advent of formal schooling as it is known now, the indigenous educational practices moulded successful and dependable members of the community. It is the suggestion of this article that because these practices aim at fostering the holistic development of the child, they are a suitable way of transitioning the child from the home environment to the formal schooling environment.

With the success of the child as the driving force for (ECDE) programmes, there is a need to re-examine these learning dynamics in the lives of the children at a time when they are transitioning to ECDE programmes in Africa. As already mentioned, it is common for older siblings, mothers, house helps, grandmothers and relatives to give care to young children in Africa (Oburu 2004; Swadener 1996). These caregivers often utilise indigenous methods at their disposal to instruct and motivate the young in their charge. This may be the case but there has been little research to investigate the dynamics and impacts of these practices on early childhood education development (Weisner 1987; 1989a; 1989b; 1997; Weisner \& Gallimore 1977).

The article, apart from suggesting that more indigenous practices be incorporated in ECDE programmes, also advocates for increased local community participation in these centres. Increased participation may open up avenues through which such centres let in aspects of indigenous care giving and motivation practices into the activities of the ECDE centres. Studies earlier quoted have shown that when ECDE centres are receptive of ideas from the community, the children enrolled receive better development and educational experience. The local community may be invited for engagement in the centre right from its inception to when it is fully operational. This engagement would enhance ownership of the centre and thus community goodwill for the same.

It is interesting, though, that hardly any studies have explored the place of these indigenous motivational systems in preparing children for formal schooling yet preschools are found in all places in the country including even the remotest parts of Kenya. It is the suggestion of this article that studies be conceptualised to investigate the possibility of incorporating the indigenous and motivational care practices to the formal ECDE curriculum in Kenya. Such a study would progress by first surveying and collecting the indigenous care practices. The study would then explore ways in which to adapt selected aspects of these care and motivational practices into the ECDE programme. 
The study could eventually be utilised by policy-makers to make appropriate suggestions to ECDE curriculum developers about aspects of the indigenous practices to adapt. It is the belief of this article that children transitioned in this way to formal schooling would stand a better chance of succeeding in the tasks required of them at these levels.

\section{Acknowledgements Competing interests}

The authors declare that they have no financial or personal relationships which may have inappropriately influenced them in writing this article.

\section{Author's contributions}

All authors equally contributed to the research and writing of this article.

\section{References}

Arnett, J.J., 2008, 'The neglected 95\%: Why American psychology needs to become less American', American Psychologist 63, 602-614. http://dx.doi.org/10.1037/ 0003-066X.63.7.602

Githinji, F. \& Kanga, A., 2011, 'Childhood development education in Kenya: A review of current issues', International Journal of Current Research 3(11), 129-136.

Indakwa, E. \& Miriti, G., 2010, Models of best practices in community development based on early childhood development, Benard Van Leer Foundation, Nairobi.

Jaramillo, A. \& Mingat, A., 2008, 'Early childhood care and education in sub-Saharan Africa: What would it take to meet the millennium development goals?' in M. Garcia, A. Pence \& J.L. Evans (eds.), Africa's future, Africa's challenge: Early childhood care and development in sub-Saharan Africa, pp. 51-70, The World Bank Washington, DC

Kenyatta, J., 1965, Facing Mount Kenya, Vintage Books, New York.

KIE, 2002, Early childhood care and education in Kenya: A report of an evaluation of UNICEF, KIE, Nairobi.

Marfo, K., Pence, A., LeVine, R.A. \& LeVine, S., 2011, 'Strengthening Africa's contributions to child development research: Introduction', Child Development Perspectives 5, 104-111. http://dx.doi.org/10.1111/j.1750-8606.2011.00164.x

MOEST, 2003, National action plan on education for all, MOEST, Nairobi.

Myers, R.G., 1998, The Parent Education project in Mexico. Consultative group on ECCD, World Bank, Washington, DC.

NACECE, 2006, Guidelines for early childhood development in Kenya, KIE, Nairobi.

Nsamenang, A.B., 1992, Human development in a cultural context: A third world perspective, Sage, Newbury Park, CA
Nsamenang, A.B., 2004, Cultures of human development and education: Challenges to growing up African, Nova, New York.

Nsamenang, A.B., 2006, 'Cultures in early childhood care and education', paper commissioned for the EFA Global Monitoring Report 2007, Strong Foundations: Early Childhood Care and Education, UNESCO, Paris.

Nsamenang, A.B., 2008, '(Mis) Understanding ECD in Africa: The force of local and global motives', in M. Garcia, A. Pence \& J.L. Evans (eds.), Africa's future, Africa's challenge: Early childhood care and development in sub-Saharan Africa, pp. 135-141, The World Bank, Washington, DC.

Oburu, P., 2004, Social adjustment of Kenyan orphaned grandchildren, perceived caregiving stresses and discipline strategies used by their fostering grandmothers, Department of Psychology, Göteborg University, Sweden.

Rogof, B., 2003, The cultural nature of human development, Oxford University Press, Oxford.

Schweinhart, L., Barnes, H. \& Weikart, D., 1993, Significant benefits: The high/scope Perry Preschool study through age 27, High/Scope Press, Ypsilanti, MI.

Segall, M.H., Dasen, P.R., Berry, J.W. \& Poortinga, Y.H., 1999, Human behavior in global perspective, Allyn \& Bacon, Boston, MA.

Sifuna, N., 1990, Development of Education in Africa: The Kenyan experience, Initiatives, Nairobi.

Swadener, B., 1996, Does the village raise the child? A collaborative study of changing child-Rearing and community mobilization in Kenya, Paper presented at the American Educational Research Association (AERA), April 9th 1996, at the American York City.

UNESCO, 2005, Policy review report: Early childhood care and education in Kenya, Early childhood and family policy series $N^{\circ} 11$, pp. 1-45.

Van Der Gaag, J. \& Tan, J.P., 1998, The benefits of early childhood development Programs: An economic analysis, World Bank, Washington, DC.

Vygotsky, L., 1968, Mind in society, Harvard University Press, Cambridge, MA.

Wadende, P., 2011a, 'Chwuech Manimba: Indigenous creative education among women of the Luo Community of Western Kenya', Theses and DissertationsCounseling, Leadership, Adult Education, and School Psychology, viewed n.d. from https://digital.library.txstate.edu/handle/10877/4127

Wadende, P., 2011b, 'Chwuech: Sustained art education among Luo women of Western Kenya', Journal of Adult and Continuing Education 17(2), 5-16. http://dx.doi.org/10.7227/JACE.17.2.3

Weisner, T.S., 1997, 'Support for children and the African family crisis', in T.S. Weisner, C. Bradley \& C.P. Kilbride (eds.), African families and the crisis of social change, pp. 20-44, Bergin \& Garvey, Westport, CT.

Weisner, T., 1989a, 'Social support for children among the Abaluyia of Kenya', in D. Belle (ed.), Children social networks and social support, pp. 70-90, Wiley, New York.

Weisner, T., 1989b, 'Comparing sibling relationship across culture', in P. Zukow (ed.), sibling interactions across cultures: Theoretical and methodological issues, pp. 11-25, Springer-Verlag, New York.

Weisner, T., 1987, 'Socializing for parenthood in sibling caretaking societies', in J. Lancaster, A. Rossi, J. Altman \& L. Sherrod (eds.), Parenting across the lifespan, pp. 237-270, Aldine Press, New York.

Weisner, T. \& Gallimore, R., 1977, 'My Brother's keeper: Child and sibling caretaking', Current Anthropology 18(2), 169-190. http://dx.doi.org/10.1086/201883 